\title{
Knowledge management approaches of small and medium- sized firms: a cluster analysis
}

\author{
Vlad Andrei Alexandru, Ettore Bolisani, Andreia Gabriela Andrei, \\ Juan Gabriel Cegarra-Navarro, Aurora Martínez Martínez, \\ Marco Paiola, Enrico Scarso, Elena-Mădălina Vătămănescu and \\ Malgorzata Zieba \\ (Author affiliations can be found at the end of the article)
}

Knowledge management approaches

Received 29 March 2019 Revised 20 August 2019 Accepted 16 September 2019

\begin{abstract}
Purpose - This paper aims to categorise the approaches to knowledge management (KM) by companies. In the literature, there is no consensus on a universal or "best" approach to KM. Especially, this paper singles out and discusses the variegated features that characterise the implementation of KM by small- and mediumsized enterprises (SMEs) having different characteristics.

Design/methodology/approach - A cluster analysis was used to detect the possible distinct traits of companies that have different approaches to KM. The unit of analysis is represented by small- and medium-sized knowledge intensive business services (KIBS) firms. Data were collected by means of an extensive survey of 223 companies in different European countries and sectors.
\end{abstract}

Findings - Three clusters were identified: Companies showing a relative "unconscious" attention to KM and implementing KM practices without particular awareness; Companies adopting a more conscious approach and using a significant number of KM practices; and companies with a marginal propensity towards KM.

Research limitations/implications - This study considers only KIBS, and future research should include other economic sectors. In addition, a convenience sample was used.

Practical implications - This paper improves awareness of managers of small companies concerning different KM approaches that can be adopted. It highlights that a conscious adoption of a KM strategy involves the introduction of a set of consistent practices.

(C) Vlad Andrei Alexandru, Ettore Bolisani, Andreia Gabriela Andrei, Juan Gabriel Cegarra-Navarro, Aurora Martínez Martínez, Marco Paiola, Enrico Scarso, Elena-Mădălina Vătămănescu and Malgorzata Zieba. Published by Emerald Publishing Limited. This article is published under the Creative Commons Attribution (CC BY 4.0) licence. Anyone may reproduce, distribute, translate and create derivative works of this article (for both commercial and non-commercial purposes), subject to full attribution to the original publication and authors. The full terms of this licence may be seen at http://creativecommons.org/licences/by/4.0/legalcode

For this work, Elena-Madalina Vatamanescu and Vlad-Andrei Alexandru were supported by a grant from the Ministry of Research and Innovation, CNCS-UEFISCDI, project number PN-III-P11.1-TE-2016-0232, within PNCDI III. Ettore Bolisani and Enrico Scarso acknowledge the financial support of the project "Developing an assessment tool to support Lean Transformation in SMEs" (PANI_SID17_01) funded by the University of Padova. Malgorzata Zieba gratefully acknowledges support from the National Science Centre (Poland) in the context of the research project "Knowledge management strategies and their determinants in companies from the knowledge-intensive business service sector" (No. 2016/21/B/HS4/03051).

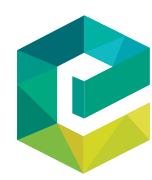

Kybernetes Vol. 49 No. 1,2020 pp. $73-87$
Emerald Publishing Limited 0368-492X DOI 10.1108/K-03-2019-0211 
$\mathrm{K}$

49,1

Originality/value - The topic of KM approaches by small companies is still underdeveloped in the literature. Also, the paper proposes a multi-contextual investigation that makes it possible to highlight the transversality of KM approaches across different countries or sectors.

Keywords Knowledge management, SMEs, KIBS, Strategic adoption, Cluster analysis

Paper type Research paper

\section{4}

\section{Introduction}

The challenges of today's economy imply a redefinition of companies and their relationships with clients, suppliers and business partners. Facing the dynamics of innovation and markets requires that organisations exchange knowledge effectively, both with internal and external entities. On the other hand, exploiting and protecting the competencies developed internally is, as well, crucial. All this means that companies need to approach knowledge management (KM) appropriately. This is crucial in the case of knowledge-intensive small- and mediumsized enterprises (SMEs), where tangible resources are scarcer in comparison to the bigger companies, and more concerned with learning than accountability (Gronum et al., 2012)

However, after more than two decades of research in KM, there is no consensus among scholars or practitioners on a universal or "best" approach to KM for all organisations, especially in the case of the smaller companies (Greiner et al., 2007). Therefore, there is still the need to achieve better understanding on this point and, particularly, to single out different possible KM approaches and their traits.

This study addresses this issue with reference to SMEs because research about KM in SMEs is relatively scarce (Centobelli et al., 2017) and does not provide ultimate results (Durst and Edvardsson, 2012; Massaro et al., 2016). This literature shows that there are some common views of how SMEs implement KM; they are often considered to be less advanced in dealing with $\mathrm{KM}$, to lack formal KM strategies and to place more emphasis on tacit knowledge. However, all these arguments need to be confirmed by appropriate empirical research.

To improve our understanding about this issue, this study aimed to single out recurring approaches to KM by SMEs, their distinctive traits and possible connections with structural characteristics of companies. A cluster analysis was performed to examine the specific features that characterise small companies in their planning, implementation and use of KM. The unit of analysis is represented by small- and medium-sized knowledge-intensive business services (KIBS) firms, which constitute an increasingly important sector of todays' economy and appear to be a particularly relevant object of analysis. Their competitiveness, indeed, is substantially based on their cognitive assets and their KM processes (PalaciosMarques et al., 2011; Miles et al., 2018; Strambach, 2010).

The data used in the cluster analysis were collected by means of an extensive survey of more than 200 companies located in four different European countries (Italy, Poland, Romania and Spain) and operating in different KIBS sectors. A structured questionnaire was submitted to key informants of these companies, with questions about origin, restraints, promoters, scope, universality, formality and adaptability of the KM practices carried out. Responses were collected between November 2016 and October 2017.

The cluster analysis made it possible to single out three different groups of companies in relation to their KM approach; they have been labelled as "conscious adopters", "unconscious adopter" and "marginal adopters." This suggests that SMEs cannot be considered as a homogeneous sector as regards KM. Furthermore, contrary to what may be expected, structural characteristics (such as sector, size and age) do not seem to exert any notable influence on the KM approach adopted by a company. 


\section{Background}

In recent decades, KM has been an important innovation in management (Inkinen et al., 2015). Indeed, effective KM can bring potential benefits such as better communication, improved customer service, faster response time, enhanced innovativeness, greater efficiency of processes and procedures as well as reduced risk of loss of critical capabilities (Wong and Aspinwall, 2004; Handzic, 2004; Edvardsson and Durst, 2013). KM initiatives can also lead to skill increase and staff retention (Migdadi, 2009; Wei et al., 2011), can have a positive influence on human capital, bring about business opportunities and facilitate new product development (Edvardsson and Oskarsson, 2011). However, there is still no consensus among scholars or practitioners on a universal or "best" approach to KM that can fit all organisations - different ways to approach KM have been identified in the single context of application (Choi and Lee, 2003; Hansen et al., 1999; Leidner et al., 2006; von Krogh et al., 2001). Furthermore, while KM has been often considered to be a deliberate activity based on formal plans, predefined processes and explicit resource allocation (Razmerita et al., 2016), some studies (Van den Hooff and Huysman, 2009; Zieba et al., 2016) show that informality and occasional problem-driven solutions may prevail. Therefore, there is still the need to achieve better understanding of this issue and, particularly, to investigate the different possible KM approaches that companies can adopt.

$\mathrm{KM}$ practices are gaining more and more attention not only in large but also in small companies (Tunc Bozbura, 2007; Wei et al., 2011). For SMEs, the implementation of KM initiatives may be even more crucial (Dotsika and Patrick, 2013; Desouza and Awazu, 2006), as knowledge can be their key resource for growth (Salojärvi et al., 2005). However, according to recent literature reviews, the studies that examine KM in the context of small businesses are still insufficient (Durst and Edvardsson, 2012; Ribière and Walter, 2013) and offer fragmented insights (Massaro et al., 2016; Durst and Bruns, 2018). Hence, there are several themes that deserve to be addressed, for example, there is the need for cross-country comparisons (Durst and Edvardsson, 2012; Massaro et al, 2016), for empirical investigations that consider SME heterogeneity (Durst and Bruns, 2018) and also for studies questioning consolidated views (Massaro et al., 2016).

Smaller firms have some unique features (e.g. limited financial and human resources, centralized management, focus on day-to-day operations and short term strategy) that deeply influence the way they operate (Torrés and Julien, 2005) and can potentially constrain their propensity to introduce KM practices. Their managers may not be prepared to invest their limited resources in KM initiatives, which may imply relatively long-term goals and whose added value can be difficult to assess in advance (Nunes et al., 2006). Conversely, SMEs possess some peculiar organisational features (i.e. a flat and flexible structure, an informal management style and, often, a high innovation potential; Hudson et al., 2001) that might, in principle, stimulate and support knowledge-sharing processes.

Many studies (Nunes et al., 2006; Hutchinson and Quintas, 2008; Edvardsson, 2006; Wong and Aspinwall, 2004) show that, when KM practices are used in a small company, this is mainly done in an informal way, without explicit plans or purposely designed information and communications technology (ICT) systems (Wee and Chua, 2013). Still, according to Coyte et al. (2012), even when a formally documented and deliberately labelled KM strategy is missing, the management of knowledge resources is somewhat governed by an informally managed organisational strategy. Indeed, many small companies end up using KM on an operational level (i.e. at the level of specific daily problems that employees must face) and, hence, they might not even recognise their practices as KM (Salojärvi et al., 2005). However, while many authors underline the informal and unplanned nature of KM in small companies, recent studies (Bolisani et al., 2016) also show that this is not always the case. 
$\mathrm{K}$

49,1

To sum up, the question on whether and how small firms introduce KM and what are the characteristics of their approach to KM is open, and further studies are needed. This paper contributes to filling this gap through the investigation of the KM approaches of small KIBS companies. The term KIBS denotes private companies whose job comprises collecting, generating, analysing and distributing knowledge with the purpose to develop customised services to business clients (Miles, 2005). These companies are characterised by three key knowledge-related features (Muller and Doloreux, 2009; Strambach, 2010):

(1) Knowledge is not only their key production factor but also the kind of "good" they sell.

(2) The provision of their services requires an in-depth interaction between supplier and client, who are both involved in mutual and cumulative learning processes.

(3) They all perform an activity of consulting, under the form of a problem-solving process where they adapt their expertise and knowledge to the specific requirements of the individual client firm.

Particularly, this study investigated the KM approaches of small KIBS companies located in four European countries and operating in different sectors. Three reasons justify this choice. First, KIBS competitiveness is likely to be based on effective use of KM practices (PalaciosMarques et al., 2011; Lara et al., 2012; Mangiarotti, 2012), because knowledge is their key factor. Second, the KIBS sector is mostly composed of small businesses (Miles et al., 2018), and this is the target of our analysis. Third, by using an internationally wide and multisector sample, the study responds to the previously recalled lack of cross-country comparisons and is also based on a potentially more heterogeneous sample of companies (Durst and Edvardsson, 2012).

\section{Research questions and method}

Small- and medium-sized European companies are weak and in many cases lack the resources that large companies have for knowledge-sharing and networking (Bolisani and Scarso, 2016; Čivre and Gomezelj Omerzel, 2015; Jordão and Novas, 2017). Therefore, based on what has been illustrated in the previous section, an exploratory research is important to address the following research questions:

$R Q 1$. Is it possible to identify some recurring KM approaches adopted by SMEs?

$R Q 2$. What are the main characteristics of these approaches?

RQ3. Do companies following the same approach share some structural traits?

Exploratory research was considered suitable for the purpose of the study, because the investigated issue had not been sufficiently explored and there was the need to gather preliminary information to define problems and suggest hypotheses (Shields and Rangarajan, 2013). In particular, a survey and a cluster analysis were conducted to detect the possible existence of groups of companies sharing a common approach to KM (Ketchen and Shook, 1996; Ketchen et al., 2008).

Given the aims of the investigation, a convenience sample was used. Despite its limitations, this is a widely adopted method in social research, and is particularly recommended in the case of exploratory studies (Leiner, 2017). In detail, a "convenience pool" was used; more precisely, respondents were selected from many convenience samples (equal to the number of sectors by the number of countries) in a respondent pool, which 
allowed to overcome one of the most critical biases of this method - the sample's homogeneity (Leiner, 2017).

The survey was conducted between November 2016 and October 2017 and involved micro-, small-, and medium-sized KIBS firms located in the four European countries of the research group's members: Italy, Poland, Romania and Spain. The initial sample comprised 223 firms belonging to five main KIBS sub-sectors, namely, ICT services, technical services, professional services, marketing and communication services and R\&D services (plus a residual "other" field for additional minor areas).

Companies were contacted through direct and personal acquaintance of researchers, or by using generic databases. Different contact methods were used (by phone, by email and also in person) to meet the preferences of respondents; these were owners (25.7 per cent of the contacted companies), executives (18.9 per cent), managers (18.9 per cent) or prominent professionals (36.5 per cent). In any case, an assessment of their importance in the company, at least for the goal of the research, was also undertaken, based on secondary data and indirect knowledge.

The survey made use of a questionnaire, compiled by drawing inspiration from previous empirical studies of the categories of KM planning approaches followed by small companies (Bolisani et al., 2015; Zieba et al., 2016). In particular, the questionnaire included 22 questions divided into different topics, that investigated companies' knowledge strategies; practices used to manage knowledge; reasons, promoters and barriers to their introduction; role of ICT applications; levels of formalization, voluntarism, adaptability, integration of KM practices with other tools and methods; diffusion across the company of the introduced practices; and, finally, companies' level of familiarity with KM concepts and applications. For lack of space, the complete questionnaire cannot be reported. However, the tables that illustrate the findings include the variables used in the cluster analysis, which correspond to the questions used in the survey. Further details are also provided in the next section.

After the collection of the responses, the data set was checked for congruity and integrity, by eliminating mistakes and incomplete records, and then coded for statistical elaboration with SPSS 18. To avoid inconsistent answers (especially in the case of smaller firms), most of the micro-sized companies were eliminated, and the analysis took into account only firms with more than four employees. This resulted in a final sample of 216 firms (Tables I and II),

\begin{tabular}{lcccccccr}
\hline Sample composition & ICT & R\&D & Tech. & Prof. & Mkg. & Other & Total & $\begin{array}{r}\text { Table I. } \\
\text { Main descriptive }\end{array}$ \\
\cline { 1 - 4 } Number of companies & 104 & 5 & 30 & 33 & 37 & 7 & 216 & characteristics of the \\
\% distribution & 48.1 & 2.3 & 13.9 & 15.3 & 17.1 & 3.2 & 100.0 & char \\
Average size & 51 & 30 & 65 & 41 & 37 & 55 & 49 & final sample (by \\
Average age & 16.6 & 9.4 & 15.4 & 13.5 & 13.0 & 14.1 & 15.1 & sector) \\
\hline
\end{tabular}

\begin{tabular}{|c|c|c|c|c|c|c|}
\hline Sample composition & Italy & Poland & Romania & Spain & Total & Table II. \\
\hline Number of companies & 59 & 41 & 51 & 65 & 216 & Main descriptive \\
\hline$\%$ distribution & 27.3 & 19.0 & 23.6 & 30.1 & 100.0 & characteristics of the \\
\hline Average size & 44 & 65 & 50 & 42 & 49 & final sample (by \\
\hline Average age & 17.0 & 15.8 & 11.3 & 16.0 & 15.1 & country) \\
\hline
\end{tabular}


$\mathrm{K}$

49,1

78

Table III.

Matrix of extracted factors (values below 0.40 are blanked) whose size ranges from 5 to 250. According to the definition of the European Community, these are micro-, small- and medium-sized enterprises.

\section{Results and discussion}

To detect the variables that better explain the behaviour of the sample, we conducted a preliminary ANOVA analysis of the data set. Analysing the variance of multiple variables made it possible to isolate the group of variables that causes the major part of the differences among firms, in terms of their KM strategies: eight variables were identified as relevant. Moreover, to reduce the complexity of the analysis, it was decided to run an exploratory factor analysis basing on the principal component method.

The variable "efforts/activities devoted to managing knowledge" summarises the answer given to a group of questions aimed at assessing how much a company considers knowledge a competitive resource and takes care of its management. The value of this variable is between 6 and 30, where 30 indicates that the company manages its knowledge at the highest level. The variable "number of adopted KM-related practices" indicates the number of practices adopted by the company and assumes a value between 0 and 10 , while the variable "barriers to the use of the practices" is the sum of the importance given to six different barriers. Its value ranges from 6 to 30, where 6 means that the six barriers are all considered as not significant and 30 means that they are considered highly significant. The value of the variable "executives are the key promoters of practices" ranges between 1 and 3 , and it increases with the importance of executives as key promoters of KM. The remaining variables (i.e. "presence of employees specifically devoted to KM, "knowledge types and sources have been identified", "acquaintance with KM concepts and applications" and "voluntarism in using KM-related practices") range between 1 and 6, where 6 means that the related aspect is at its maximum.

As it can be seen in Table III (that reports the rotated factor matrix obtained via the Varimax method and Kaiser normalisation), the mentioned variables were consequently reduced to three uncorrelated factors that explain 62.23 per cent of the total variance, and in particular, 32.8 per cent the first factor, 16.8 per cent the second factor and 12.63 per cent the third factor.

Each factor represents a meta-variable that cumulates the effects of different single variables, which contribute to explain a specific characteristic of firms (correlated variance), and in addition depicts a particular trait of the whole sample behaviour (overall variance). Therefore, they share a common meaning that was named in a more explicative and representative form with the labels: "activism", "spontaneity" and "imposition".

\begin{tabular}{lccc}
\hline Variables & $\begin{array}{c}\text { Factor 1 } \\
\text { "activism" }\end{array}$ & $\begin{array}{c}\text { Factor 2 } \\
\text { "spontaneity" }\end{array}$ & $\begin{array}{c}\text { Factor 3 } \\
\text { "imposition" }\end{array}$ \\
\hline Efforts/activities devoted to managing knowledge & 0.913 & & \\
Presence of employees specifically devoted to KM & 0.759 & & \\
Knowledge types and sources have been identified & 0.729 & & \\
Acquaintance with KM concepts and applications & 0.624 & & \\
Number of adopted KM-related practices & 0.474 & 0.724 & 0.595 \\
Voluntarism in using KM-related practices & & -0.607 & 0.696 \\
Executives are the key promoters of practices & & & \\
Barriers to the use of the practices & & &
\end{tabular}


The first factor, "activism", points out a pro-active attitude of companies toward the management of their cognitive resources, that leads to devote specific efforts to numerous KM-related initiatives, particularly the identification of the types and sources of useful knowledge for their business, and the use of specific staff devoted to KM. Such efforts are driven by substantial awareness of KM notions and applications. Activism implies the adoption of a variegated set of tools and KM-related practices. The second factor, "spontaneity", accounts for a bottom-up and expectedly less formalised approach to the introduction of KM. Spontaneity reflects a voluntary use of the practices by employees, which often favours and promotes their adoption. Finally, the third factor, "imposition", accounts for a top-down approach to the introduction of KM activities, substantially driven by the willingness of owners and executives who, consequently, become more sensitive to the obstacles to their initiative.

By using the extracted factors, a non-hierarchical ( $k$-means) cluster analysis was performed to classify the sampled companies into similar groups. This method provided three clusters (scores for each factor are shown in Table IV - in parenthesis the number of firms within each cluster, with seven companies that could not be included in any cluster). The distribution of companies in the different clusters is rather uniform, although the most populated cluster is the first one (37 per cent of companies), while the least populated is the third one (around 31 per cent of the sample). Therefore, there does not seem to be one prevalent behaviour.

Table IV provides some synthetic information regarding the identified groups, with the presence of negative or positive values that clearly denote the nature of each cluster. Table $\mathrm{V}$ adds more details by showing the results of an ANOVA variance analysis of the eight original variables across the identified clusters.

To improve the understanding of the distinctive traits of the three clusters, a further descriptive analysis of the variables "number of adopted KM-related practices" and "barriers to the use of the practices" was done, by investigating the distribution of their components. In this regard, Table VI shows the diffusion of the individual KM practices within each cluster, which underlines that the difference in the level of adoption between the different clusters mainly regards the adoption of those practices that are generally

\begin{tabular}{|c|c|c|c|c|}
\hline Factors & Cluster 1 (77) & Cluster 2 (68) & Cluster 3 (64) & $\begin{array}{l}\text { Cluster centres } \\
\text { values (the number of }\end{array}$ \\
\hline Factor 1 & 0.73308 & -0.62716 & -0.21563 & each cluster's \\
\hline Factor 2 & 0.55436 & -0.51978 & -0.11469 & members is indicated \\
\hline Factor 3 & 0.31105 & 0.68795 & -1.10518 & between parentheses) \\
\hline
\end{tabular}

\begin{tabular}{lrrrrr}
\hline Variable & Cluster 1 & Cluster 2 & Cluster 3 & Whole sample & \\
\hline Efforts/activities devoted to managing knowledge & 24.74 & 19.16 & 21.16 & 21.83 & \\
Presence of employees specifically devoted to KM & 3.66 & 2.28 & 2.94 & 2.99 & \\
Knowledge types and sources have been identified & 4.31 & 3.29 & 3.52 & 3.74 & Table V. \\
Acquaintance with KM concepts and applications & 3.96 & 2.82 & 3.16 & 3.34 & Average values of \\
Number of adopted KM-related practices & 6.92 & 6.35 & 5.50 & 6.30 & the considered \\
Voluntarism in using KM-related practices & 3.60 & 2.65 & 2.45 & 2.94 & variables for the \\
Executives are the key promoters of practices & 2.22 & 2.82 & 1.72 & 2.26 & identified clusters \\
Barriers to the use of the practices & 18.58 & 18.91 & 13.89 & 17.25 & \\
\hline
\end{tabular}


$\mathrm{K}$

49,1

80

considered the "most KM specific" (for instance, adopting communities of practice, rewarding the sharing of knowledge and creating a supportive environment).

In the same way, Table VII shows the average importance (on a scale from 1 to 5 ) assigned by companies of each cluster to the different barriers. Cluster 1 and Cluster 2 appear to be very similar, and both differ from Cluster 3, where the perception of barriers results to be significantly lower. On the whole, however, barriers are generally considered relatively insignificant, apart from the lack of time, which apparently represents an effective obstacle to KM practices.

Cluster 1, which will be denominated as "conscious adopters," includes companies characterised by an intentional and active management of their knowledge assets. These companies have analysed and identified the types and sources of knowledge that are used for their business and have one or more employees specifically devoted to KM-related practices. This can be explained by considering that they declare to have a more than good acquaintance with KM concepts. Their attention to KM is confirmed by the introduction of a relevant number of practices, including those that are more KM-specific (Table VI), as e.g. rewarding employees who share knowledge (44.2 per cent - this point greatly differentiates conscious adopters form the other two groups), storing knowledge in electronic repositories (88.3 per cent), creating a supportive environment for sharing knowledge (75.3 per cent), and employing communities of practice (48.1 per cent). Promoters of introduction are both executives and employees (their role as promoters has been indicated by the 46.8 per cent of respondents), and their use is mainly on a voluntary basis, probably because employees also play a role in the promotion of KM practices. Companies of Cluster 1 have encountered some moderate barriers to KM practices, and this can be due to the significant number of adopted

Table VI.

Percentages of companies of each cluster that have introduced the indicated practices

\begin{tabular}{lcccc}
\hline KM practices & $\begin{array}{c}\text { Cluster 1 } \\
(\%)\end{array}$ & $\begin{array}{c}\text { Cluster 2 } \\
(\%)\end{array}$ & $\begin{array}{c}\text { Cluster 3 } \\
(\%)\end{array}$ & $\begin{array}{c}\text { Whole } \\
\text { sample (\%) }\end{array}$ \\
\hline Capturing/storing knowledge in electronic repositories & 88.3 & 76.5 & 71.9 & 79.4 \\
Email for knowledge sharing and transferring & 84.4 & 92.6 & 82.8 & 86.6 \\
Social media for publishing and accessing information & 66.2 & 69.1 & 54.7 & 63.6 \\
Building and maintaining employees' expertise & 80.0 & 76.5 & 75.0 & 77.5 \\
Dissemination of best practice & 66.2 & 64.7 & 51.6 & 61.2 \\
Creating a knowledge-sharing supportive environment & 75.3 & 66.2 & 62.5 & 68.4 \\
Rewarding employees who share their knowledge & 44.2 & 27.9 & 26.6 & 33.5 \\
Organizing meetings to share information & 77.9 & 77.9 & 62.5 & 73.2 \\
Using ERP or CRM software & 61.0 & 51.5 & 40.6 & 51.0 \\
Using communities of practices to share knowledge & 48.1 & 32.4 & 21.9 & 34.1 \\
Total (\%) & 69.2 & 63.5 & 55.0 & 63.0 \\
\hline
\end{tabular}

Table VII.

Barriers to the practice by cluster

\begin{tabular}{lcccc}
\hline Barriers & Cluster 1 & Cluster 2 & Cluster 3 & Whole sample \\
\hline Limited financial resources & 3.34 & 3.12 & 2.22 & 2.92 \\
Limited human resources & 3.42 & 3.53 & 2.72 & 3.24 \\
Lack of specialists & 3.01 & 3.46 & 2.23 & 2.92 \\
Insufficient number of users & 2.53 & 2.60 & 1.78 & 2.33 \\
Lack of time to devote to KM & 3.71 & 3.74 & 2.97 & 3.49 \\
Resistance of employees to their use & 2.57 & 2.47 & 1.97 & 2.35 \\
Whole sample (average) & 3.10 & 3.15 & 2.30 & 3.15 \\
\hline
\end{tabular}


practices. To sum up, firms of this cluster are consciously managing their knowledge, and apparently tend to spread this awareness of the importance of KM among their staff, considering that they also leave part of the specific KM practices up to the employees' initiative.

Cluster 2, labelled as "unconscious adopters", includes companies characterised by a relative low attention to knowledge and KM, probably because they have an insufficient acquaintance of KM concepts. In particular, they do not make special efforts to identify types and sources of useful knowledge, neither they have employees that are specifically devoted to KM. However, they declare the adoption of a good number of KM practices, even though they are often less specific in KM terms (Table VI), as e.g. email (adopted in 92.6 per cent of cases) or meetings (77.9 per cent). In other words it may be assumed that companies of Cluster 2 have introduced these practices because they consider them useful to their business in general, but without making a direct reference to KM itself. The adoption of these practices has been largely promoted by executives and owners ( 83.8 per cent of cases) and is substantially mandatory for the staff. This can also explain why these companies consider the barriers to adoption to be more important, compared to the other clusters. To sum up, companies belonging to Cluster 2 do manage their knowledge, and owners/ managers have a key role in this, but without being really aware of what they are doing. In other words, this cluster seems to be populated by firms that invest more in the formal adoption of some practices than in creating the proper organisational context where these can be exploited effectively. Managers demand employees to use KM practices but do not commit the entire firm in building a strong understanding of KM fundamentals.

Cluster 3, named as "marginal adopters", includes companies characterised by a "neutral" propensity toward KM, especially by executives and owners. They introduced a lower number of KM practices, and employees are their main promoters (45.5 per cent of cases). This cluster makes the least use of KM-specific practices, especially "rewarding employees who share knowledge" (26.6 per cent), as well as resorting to communities of practice (21.9 per cent). Marginal adopters also make a significantly lower use of meetings (62.5 per cent) and social media (57.4 per cent) in comparison to the other companies. Furthermore, even though KM practices have been introduced thanks to the action of employees, their use becomes rather mandatory. This can be explained by arguing that practices are first introduced by employees occasionally (to solve their specific daily problems) but later become the standard use in the company. Cluster 3 also differs from the others as regards the barriers to introduction that are considered not significant. This can be explained by considering that these companies adopted a limited number of KM practices. To sum up, the third cluster is populated by firms that do not seem to be interested and/or equipped for investing actively and deliberately in KM instruments and strategies.

We need now to verify whether the companies that belong to a specific cluster share similar structural characteristics, in terms of sector, size and age. To make this analysis, the "R\&D" and the "other services" categories were left out, because the figures are very marginal.

As Table VIII shows, the companies of different sectors are quite evenly distributed across the single clusters. This is an important point - it is hard to affirm that there is a clear and univocal relationship between the belonging to a specific sector and the belonging to a specific cluster. In other words, no cluster - and therefore no specific orientation toward KM - can be clearly identified based on the KIBS sector of a company. In substance, the findings of the cluster analysis confirm the assertion of previous studies (Bolisani et al., 2014; Pina and Tether, 2016) that the sector alone is not enough to reveal the approach and orientation of a company toward KM. Conversely, the traits of the clusters deeply challenge the typical views of KIBS based on a popular classification between T-KIBS and P-KIBS (Miles et al., 2018). T-KIBS are 
$\mathrm{K}$

49,1

the technology-based services (e.g. ICT, engineering and architecture) and P-KIBS are the professional services (e.g. legal services, fiscal services and advisory services). In the case of our companies, the largest share of the "engineering and architecture" (i.e. technical services) companies and of the professionals services companies - which should be considered T-KIBS and P-KIBS respectively - both belong to the third cluster. Instead, the largest share of ICT companies (typically included in the T-KIBS category) belongs to the first cluster. This shows that there is no consistent description of companies of the same category if we consider their KM approach.

Considering the size composition of the three clusters (Table IX), again there is no clear relationship between size and cluster. It is true that micro firms (with a size between 5 and 9 employees) appear more in the third cluster - which is sensible, given that the smallest firms have smaller needs and resources to adopt and use knowledge management tools and practices. But the distribution of small (10- 49 employees) and medium-sized firms $(\geq 50$ employees) is much less marked and, in any case, contradictory. One would expect that large companies would be relatively more conscious adopters than small companies, but this is not what happens. In short, the size of a company is not a clear factor for predicting its inclusion in a specific cluster (in other words, its KM orientation).

Similarly, as regards the age of companies, there is no clear difference between clusters. Companies of Cluster 1 and Cluster 3 practically have the same average age (14.1 and 13.9 years), and companies of Cluster 2 are just a little older (17.7 years). Finally, difficult to explain is the distribution of clusters among countries (Table X). Some studies have shown

Table VIII.

Sectoral composition of the clusters (percentage distribution in proportion to the total number of companies in the cluster)

\begin{tabular}{lcccc}
\hline Sector & Cluster 1 $(\%)$ & Cluster 2 (\%) & Cluster 3 (\%) & Whole sample (\%) \\
\hline ICT & 53.20 & 45.60 & 48.40 & 49.30 \\
Engineering and architecture & 11.60 & 11.80 & 15.60 & 12.90 \\
Professional & 14.30 & 13.20 & 18.80 & 15.30 \\
Marketing and communication & 11.70 & 23.50 & 15.60 & 16.70 \\
\hline
\end{tabular}

\begin{tabular}{lcccc}
\hline Size & Cluster 1 & Cluster 2 & Cluster 3 & Whole sample \\
\hline $5-9(\%)$ & 5.2 & 13.2 & 15.6 & 11.0 \\
$10-49(\%)$ & 63.6 & 50.0 & 54.7 & 56.5 \\
$\geq 50(\%)$ & 31.2 & 36.8 & 29.7 & 32.6 \\
Average size & 49.8 & 53.7 & 44.5 & 49.5 \\
\hline
\end{tabular}

Table IX.

Clusters composition by size

\begin{tabular}{lcccc}
\hline Country & Cluster 1 $(\%)$ & Cluster 2 $(\%)$ & Cluster 3 $(\%)$ & Whole sample $(\%)$ \\
\hline Italy & 23.73 & 37.29 & 38.98 & 28.23 \\
Poland & 18.42 & 42.11 & 39.47 & 18.18 \\
Romania & 52.94 & 35.29 & 11.76 & 29.19 \\
Spain & 47.54 & 19.67 & 32.79 & 24.40 \\
\hline
\end{tabular}


that the KM approach within a knowledge-intensive SME can be influenced by the sociocultural relationships within the country of study (Cegarra-Navarro and Sánchez-Polo, 2010; Cegarra-Navarro et al., 2011). In practice, it has been argued that relationships between managers and employees, the motivations based on rewards or costs, the widespread use of terms, such as "chief" or (conversely) "community", might be influenced by international differences in language, culture and context, which in turn can provide differing perceptions of the external environment. In the case of our sample, however, differences of KM approach based on the country of operation are difficult to detect. Just two points apparently emerge. First, the case of Romanian companies, which stand out for devoting, on the whole, a higher attention to KM than the companies located in other countries. This may be explained by considering that these are the youngest companies of the sample (and, therefore, their owners or managers can be more inclined to management innovations), but this is just a hypothesis that should be further verified. Second, a significant relevant share of Polish companies falls in Cluster 2. This may, however, depend on their size (these companies are the biggest of the sample). In substance, as also underlined by Durst and Edvardsson (2012), our analysis confirms that the issue of national differences and country comparisons is a topic that is still open.

\section{Conclusions}

This study aimed to investigate the possible ways of approaching KM adopted by small companies. Specifically, by means of a cluster analysis on a sample of more than 200 KIBS firms located in four European countries, we tried to answer three research questions related to this issue.

With respect to $R Q 1$ and $R Q 2$, the study allowed to answer both questions. Collected data, in fact, made it possible to identify three distinct approaches to KM that not only show peculiar traits but also seem to recall similar analyses and distinctions that can be found in the strategic literature (Mintzberg, 1987). These clusters were labelled as "conscious adopters", "unconscious adopters" and "marginal adopters". With respect to RQ3, the study did not highlight any specific correlation between sector, size or age and a specific KM orientation. Instead, as concerns the relationship with the geographical context of operation, what emerged from the analysis does not allow a univocal interpretation, which leaves this as an open issue. A possible explanation of the above findings may lie in a lack of familiarity with KM notions by companies and in the different options in terms of KM approaches that they can follow.

To sum up, from the academic point of view, the study helps to improve our understanding about the ways in which smaller businesses approach KM. In particular, it contributes to question some common beliefs about KM and SMEs, as the fact that smaller companies have a homogeneous, not deliberated and substantially informal approach to this management tool. Furthermore, it offers some food for thoughts also to KIBS scholars concerning the validity of the distinction between T-KIBS and P-KIBS when considering their KM approaches.

The study also provides some practical lessons. First, its findings can make managers of small companies aware of the fact that they can adopt different KM approaches. Furthermore, it highlights that a really conscious adoption of KM implies the introduction and use of a consistent set of practices. In other words, KM is not simply a matter of adopting a software tool or an electronic repository. Our results also support the argumentation that there are some differences in the way managers deal with KM barriers. Marginal adopters' companies do not find as many barriers as conscious and unconscious adopters. The underlying assumption being made here is that marginal adopters' who have hardly made use of KM structures are more unlikely 
$\mathrm{K}$

49,1

to be able to understand and see KM barriers and if these can hinder their relationship with new and potential opportunities (Pinget et al., 2015). This is also in broad agreement with the conclusions of authors, such as Filieri and Alguezaui (2009), Sánchez-Polo et al. (2019), who assert that companies need help to see barriers because otherwise they tend to jump to the most convenient conclusions consistent with their previous experience.

The study has also some limitations. On the one hand, it contributes to our understanding of how SMEs manage their knowledge; but on the other hand, given its exploratory nature, further research is needed to examine the topic more thoroughly. The factors that affect the adoption of a specific KM approach must be explained more clearly, especially to give an answer to the third research question. Aspects such as the level of customisation of the provided services, or the kind of organisational structure of a company, can be included in the analysis. Second, it should be verified if there are other elements that can be considered as common traits of the three different KM approaches. Third, the last, but not least aspect that deserves further investigations is the effect of the different KM approaches on company performance. Also, our investigation considered only KIBS companies that, by definition, are more aware of their knowledge resources and consequently devote more attention to their management. Hence, future research should include small companies belonging to other sectors such as traditional manufacturers. Finally, we used a convenience sample. While this approach can be appropriate for exploratory aims, a confirmative analysis should employ a more representative one.

\section{References}

Bolisani, E. and Scarso, E. (2016), "Factors affecting the use of wiki to manage knowledge in a small company”, Journal of Knowledge Management, Vol. 14 No. 2, pp. 423-443.

Bolisani, E., Paiola, M. and Scarso, E. (2014), "Cognitive features of KIBS companies: evidence from a cluster analysis", International Journal of Services Technology and Management, Vol. 20 Nos 4/5/6, pp. 215-223.

Bolisani, E., Scarso, E. and Giuman, L. (2016), "Knowledge management in client-supplier relationship: emergent vs deliberate approach in small KIBS", Knowledge Management Research and Practice, Vol. 14 No. 2, pp. 178-185.

Bolisani, E., Scarso, E. and Zięba, M. (2015), "Emergent versus deliberate knowledge management strategy: literature review and case study snalysis;" in Garlatti, A. and Massaro, M. (Eds), Proceedings of the 16th European Conference on Knowledge Management, Academic Conferences Limited, Reading, pp. 153-160.

Cegarra-Navarro, J.G. and Sánchez-Polo, M.T. (2010), "Linking national contexts with intellectual capital: a comparison between Spain and Morocco", The Spanish Journal of Psychology, Vol. 13 No. 1, pp. 329-342.

Cegarra-Navarro, J.G., Vidal, M.E.S. and Cegarra-Leiva, D. (2011), "Exploring the role of national culture on knowledge practices: a comparison between Spain and the UK", The Spanish Journal of Psychology, Vol. 14 No. 2, pp. 808-819.

Centobelli, P., Cerchione, R. and Esposito, E. (2017), "Knowledge management systems the hallmark of SMEs", Knowledge Management Research and Practice, Vol. 15 No. 2, pp. 294-304.

Choi, B. and Lee, H. (2003), "An empirical investigation of knowledge management styles and their effect on corporate performance", Information and Management, Vol. 40 No. 5, pp. 403-417.

Coyte, R., Ricceri, F. and Guthrie, J. (2012), "The management of knowledge resources in SMEs: an australian case study", Journal of Knowledge Management, Vol. 16 No. 5, pp. 789-807. 
Čivre, Ž. and Gomezelj Omerzel, D. (2015), "The behaviour of tourism firms in the area of innovativeness", Economic research-Ekonomska Istraživanja, Vol. 28 No. 1, pp. 312-330.

Desouza, K.C. and Awazu, Y. (2006), "Knowledge management at SMEs: five peculiarities", Journal of Knowledge Management, Vol. 10 No. 1, pp. 32-43.

Knowledge management approaches

Dotsika, F. and Patrick, K. (2013), "Collaborative KM for SMEs: a framework evaluation study", Information Technology and People, Vol. 26 No. 4, pp. 368-382.

Durst, S. and Bruns, G. (2018), "Knowledge management in small and Medium-Sized enterprises", in The Palgrave Handbook of Knowledge Management, Palgrave Macmillan, Cham., pp. 495-514.

Durst, S. and Edvardsson, R.I. (2012), "Knowledge management in SMEs: a literature review", Journal of Knowledge Management, Vol. 16 No. 6, pp. 879-903.

Edvardsson, I.R. (2006), "Knowledge management in SMEs: the case of Icelandic firms", Knowledge Management Research and Practice, Vol. 4 No. 4, pp. 275-282.

Edvardsson, I.R. and Durst, S. (2013), "Does knowledge management deliver the goods in SMESs?", Business and Management Research, Vol. 2 No. 2, pp. 52-60.

Edvardsson, I.R. and Oskarsson, G.K. (2011), "Knowledge management and value creation in service firms", Journal of Knowledge Management, Vol. 15 No. 4, pp. 7-15.

Filieri, R. and Alguezaui, S. (2009), "Intra-firm knowledge sharing barriers: state of the art", Proceedings of the European Conference on Knowledge Management, ECKM, Vicenza, 3-4 September, pp. 265-274.

Greiner, M.E., Böhmann, T. and Krcmar, H. (2007), “A strategy for knowledge management”, Journal of Knowledge Management, Vol. 11 No. 6, pp. 3-15.

Gronum, S., Verreynne, M.L. and Kastelle, T. (2012), "The role of networks in small and medium-sized enterprise innovation and firm performance", Journal of Small Business Management, Vol. 50 No. 2, pp. 257-282.

Handzic, M. (2004), "Knowledge management in SMEs", Asia-Pacific Tech Monitor, Vol. 10 No. 1, pp. 29-34.

Hansen, M.T., Nohria, N. and Tierney, T. (1999), “What's your strategy for managing knowledge?”, Harvard Business Review, Vol. 77 No. 2, pp. 106-116.

Hudson, M., Smart, P.A. and Bourne, M. (2001), "Theory and practice in SME performance measurement systems", International Journal of Operations and Production Management, Vol. 21 No. 8, pp. 1096-1116.

Hutchinson, V. and Quintas, P. (2008), "Do SMEs do knowledge management? Or simply manage what they know?", International Small Business Journal: Researching Entrepreneurship, Vol. 26 No. 2, pp. 131-154.

Jordão, R.V.D. and Novas, J.C. (2017), "Knowledge management and intellectual capital in networks of small-and medium-sized enterprises", Journal of Intellectual Capital, Vol. 18 No. 3, pp. 667-692.

Ketchen, D.J. and Shook, C.L. (1996), "The application of cluster analysis in strategic management research: an analysis and critique”, Strategic Management Journal, Vol. 17 No. 6, pp. 441-458.

Ketchen, D.J., Jr, Boyd, B.K. and Bergh, D.D. (2008), "Research methodology in strategic management: past accomplishments and future challenges", Organizational Research Methods, Vol. 11 No. 4, pp. 643-658.

Inkinen, H.T., Kianto, A. and Vanhala, M. (2015), "Knowledge management practices and innovation performance in Finland", Baltic Journal of Management, Vol. 10 No. 4, pp. 432-455.

Lara, F., Palacios-Marques, D. and Devece, C.A. (2012), "How to improve organisational results through knowledge management in knowledge-intensive business services", The Service Industries Journal, Vol. 32 No. 11, pp. 1853-1863.

Leidner, D., Alavi, M. and Kayworth, T. (2006), "The role of culture in knowledge management: a case study of two global firms", International Journal of e-Collaboration, Vol. 2 No. 1, pp. 17-40. 
$\mathrm{K}$

49,1

Leiner, D.J. (2017), “Our research's breadth lives on convenience samples a case study of the online respondent Pool "SoSci panel", SCM Studies in Communication and Media, Vol. 5 No. 4, pp. 367-396.

Mangiarotti, G. (2012), "Knowledge management practices and innovation propensity: a firm level analysis from Luxembourg”, International Journal of Technology Management, Vol. 58 No. 3/4, pp. 261-283.

Massaro, M., Handley, K., Bagnoli, C. and Dumay, J. (2016), "Knowledge management in small and medium enterprises: a structured literature review”, Journal of Knowledge Management, Vol. 20 No. 2, pp. 258-291.

Migdadi, M. (2009), "Knowledge management enablers and outcomes in the small-and-medium sized enterprises", Industrial Management and Data Systems, Vol. 109 No. 6, pp. 840-858.

Miles, I. (2005), "Knowledge intensive business services: prospects and policies”, Foresight, Vol. 7 No. 6, pp. 39-63.

Miles, I., Belousova, V. and Chichkanov, N. (2018), "Knowledge intensive business services: ambiguities and continuities", Foresight, Vol. 20 No. 1, pp. 1-26.

Mintzberg, H. (1987), “Crafting Strategy”, Harvard Business Review, July-August, pp. 66-75.

Muller, E. and Doloreux, D. (2009), "What we should know about knowledge-intensive business services", Technology in Society, Vol. 31 No. 1, pp. 64-72.

Nunes, M.B., Annansingh, F., Eaglestone, B. and Wakefield, R. (2006), "Knowledge management issues in knowledge-intensive SMEs", Journal of Documentation, Vol. 62 No. 1, pp. 101-119.

Palacios-Marques, D., Gil-Pechuán, I. and Lim, S. (2011), "Improving human capital through knowledge management practices in knowledge-intensive business services", Service Business, Vol. 5 No. 2 , pp. 99-112.

Pina, K. and Tether, B.S. (2016), "Towards understanding variety in knowledge intensive business services by distinguishing their knowledge bases", Research Policy, Vol. 45 No. 2, pp. 401-413.

Pinget, A., Bocquet, R. and Mothe, C. (2015), "Barriers to environmental innovation in SMEs: empirical evidence from french firms”, M@n@gement, Vol.18 No.2, pp.132-155.

Razmerita, L., Phillips-Wren, G. and Jain, L.C. (2016), “Advances in knowledge management: an overview", in Razmerita, L., Phillips-Wren, G. and Jain, L.C. (Eds), Innovations in Knowledge Management, Springer, Berlin Heidelberg, pp. 3-18.

Ribière, V. and Walter, C. (2013), "10 Years of KM theory and practices”, Knowledge Management Research and Practice, Vol. 11 No. 1, pp. 4-9.

Salojärvi, S., Furu, P. and Sveiby, K.E. (2005), "Knowledge management and growth in finish SMEs", Journal of Knowledge Management, Vol. 9 No. 2, pp. 103-122.

Sánchez-Polo, M.T., Cegarra-Navarro, J.G., Cillo, V. and Wensley, A. (2019), "Overcoming knowledge barriers to health care through continuous learning”, Journal of Knowledge Management, Vol. 23 No. 3, pp. 508-526.in press.

Shields, P.M. and Rangarajan, N. (2013), A Playbook for Research Methods: Integrating Conceptual Frameworks and Project Management, New Forums Press.

Strambach, S. (2010), "Knowledge-intensive business services (KIBS) - on the way towards a knowledge processing and producing industry", in Cooke, P., De Laurentis, C., MacNeill, S. and Collinge, C. (Eds), Platforms of Innovation Dynamics of New Industrial Knowledge Flows, Edward Elgar, Cheltenham, pp. 170-204.

Torrés, O. and Julien, P.A. (2005), "Specificity and denaturing of small business", International Small Business Journal: Researching Entrepreneurship, Vol. 23 No. 4, pp. 355-377.

Tunc Bozbura, F. (2007), "Knowledge management practices in turkish SMEs", Journal of Enterprise Information Management, Vol. 20 No. 2, pp. 209-221.

Van den Hooff, B. and Huysman, M. (2009), "Managing knowledge sharing: emergent and engineering approaches", Information and Management, Vol. 46 No. 1, pp. 1-8. 
von Krogh, G., Nonaka, I. and Aben, M. (2001), "Making the most of your company's knowledge: a strategic framework", Long Range Planning, Vol. 34 No. 4, pp. 421-439.

Wee, J.C.N. and Chua, A.Y.K. (2013), "The peculiarities of knowledge management processes in SMEs: the case of Singapore", Journal of Knowledge Management, Vol. 17 No. 6, pp. 958-972.

Knowledge management approaches

Wei, C.C., Choy, C.S. and Chew, G.C. (2011), "The KM processes in Malaysian SMEs: an empirical validation", Knowledge Management Research and Practice, Vol. 9 No. 2, pp. 185-196.

Wong, K.Y. and Aspinwall, E. (2004), "Characterizing knowledge management in the small business environment", Journal of Knowledge Management, Vol. 8 No. 3, pp. 44-61.

Zieba, M., Bolisani, E. and Scarso, E. (2016), "Emergent approach to knowledge management by small companies: multiple case-study research", Journal of Knowledge Management, Vol. 20 No. 2, pp. 292-307.

\section{Author affiliations}

Vlad Andrei Alexandru, Department of Economics, University of Insubria, Varese, Italy

Ettore Bolisani, Department of Management and Engineering, University of Padua, Padova, Italy

Andreia Gabriela Andrei, Alexandru Ioan Cuza University of Iasi, Iasi, Romania

Juan Gabriel Cegarra-Navarro and Aurora Martínez Martínez, Faculty of Business Sciences, Polytechnic University of Cartagena, Spain

Marco Paiola, Department of Economics and Management, University of Padua, Padova, Italy

Enrico Scarso, Department of Management and Engineering, University of Padua, Padova, Italy

Elena-Mădălina Vătămănescu, National University of Political Studies and Public Administration, Bucharest, Romania, and

Malgorzata Zieba, Gdansk University of Technology, Gdansk, Poland

\section{Corresponding author}

Ettore Bolisani can be contacted at: ettore.bolisani@unipd.it

For instructions on how to order reprints of this article, please visit our website: 